\title{
Farklı çimentolardan üretilen köpük betonlarda atık lastiklerin hafif agrega olarak kullanımı
}

\author{
Use of waste tires as lightweight aggregate in foam concrete produced from different \\ cement
}

\author{
Oğuzhan Yavuz BAYRAKTAR ${ }^{1, a}$, Gökhan KAPLAN ${ }^{2 *, b}$ \\ ${ }^{1}$ Kastamonu Üniversitesi, Mühendislik-Mimarlık Fakültesi, İnşaat Mühendisliği Bölümü, Kastamonu \\ ${ }^{2}$ Atatürk Üniversitesi, Mühendislik Fakültesi, İnşaat Mühendisliği Bölümü, Erzurum
}

\begin{abstract}
• Geliş tarihi / Received: 13.01.2021 • Düzeltilerek geliş tarihi / Received in revised form: 08.04.2021 • Kabul tarihi / Accepted: 14.04 .2021
\end{abstract}
$\ddot{O} z$

Küresel ısınmanın artmasıyla birlikte günümüzde yapıların ölü yüklerini azaltmak ve 1sı yalıtımı özelliklerini iyileştirmek için geleneksel betona alternatif çözümler aranmaktadır. Bu ihtiyaçlardan dolayı düşük birim ağırlık ve üstün termal özellikleri sahip köpük beton ön plana çıkmaktadır. Bu çalışmada, farklı çimentolar ile farklı birim ağırlığa sahip köpük betonlar üretilmiştir. Çalışma kapsamında CEM II, CEM III ve CEM IV'den oluşan kompoze çimentolar kullanılmıştır. 30,60 ve $90 \mathrm{~kg} / \mathrm{m}^{3}$ köpük içeriği ile 9 farklı karışım elde edilmiştir. Köpük betonların üretiminde agrega olarak 0-1 mm boyutunda atık lastikler kullanılmıştır. Köpük içeriği arttıkça betonların görünür porozite ve su emme değerleri artarken birim ağırlık değerleri azalmıştır. Köpük betonların birim ağılıkları $595-980 \mathrm{~kg} / \mathrm{m}^{3}$ arasında değişmektedir. 28 günlük basınç dayanımları ise $0.53-1.56 \mathrm{MPa}$ arasında değişmektedir. Köpük betonların köpük içeriği arttıkça su işleme derinliği azalmıştır. Köpük betonların su işleme derinlikleri 2.6-8.2 mm arasındadır. İki yönlü ANOVA analizi sonucunda çimento tipindeki değişim köpük beton özelliklerini etkilememektedir. Ancak köpük içeriğindeki değişim köpük beton özelliklerini doğrudan etkileyebilmektedir. CEM III tipi çimentodan üretilen köpük betonların mekanik özellikleri diğer çimento tiplerine göre daha yüksek olmaktadır. Sonuç olarak çevre ve insan sağlığı açısından zararlı olan atık lastiklerin köpük beton üretiminde kullanılabileceği belirlenmiştir. Atık lastik agregası ile üretilen köpük betonların tuğladan daha iyi bir termal özellik göstereceği tahmin edilmektedir.

Anahtar kelimeler: Atık lastik, Görünür porozite, Kılcallık, Köpük beton, Sürdürülebilirlik

\begin{abstract}
With the increase in global warming, alternative solutions to traditional concrete are being inquired today to reduce dead loads of structures and improve their thermal insulation properties. Due to these needs, foam concrete with low unit weight and superior thermal properties comes to the fore. In this study, foam concretes with different unit weight were produced with different cements. In the scope of the study, composite cements consisting of CEM II, CEM II and CEM IV were used. 9 different mixtures were obtained with foam contents of 30,60 and $90 \mathrm{~kg} / \mathrm{m}^{3} .0-1 \mathrm{~mm}$ waste tires were used as aggregate in the production of foam concretes. As the foam content increased, the apparent porosity and water absorption values of concrete increased, while the unit weight values decreased. The unit weights of foam concretes range from $595-980 \mathrm{~kg} / \mathrm{m}^{3}$. 28-day compressive strength ranges from 0.53-1.56 MPa. As the foam content of foam concretes increased, the depth of water penetration decreased. Water penetration depths of foam concrete are between 2.6-8.2 mm. As a result of two-way ANOVA analysis, the change in cement type does not affect the properties of foam concrete. But the change in foam content can directly affect the properties of foam concrete. The mechanical properties of foam concrete produced from CEM III type cement are higher than other cement types. As a result, it was determined that waste tires that are harmful to the environment and human health can be used in the production of foam concrete. It is estimated that foam concrete produced with waste rubber aggregate will show a closer thermal property than brick.
\end{abstract}

Keywords: Waste tire, Apparent porosity, Capillarity, Foam concrete, Sustainability

\footnotetext{
${ }^{* b}$ Gökhan KAPLAN; gkaplan@atauni.edu.tr, Tel: (0442) 231 4927, orcid.org/0000-0001-6067-7337

${ }^{a}$ orcid.org/0000-0003-0578-6965
} 


\section{Giriş}

Kentleşme ve sanayileşmenin hızlı büyümesi, dünya çapında ulaşım araçlarının kalitesini ve miktarını artırmıştır. LMC Automotive tarafından yapılan tahminlere göre, 2024 yılına kadar araç filosu dünya çapında $\% 25$ ten fazla artacak ve AB'de yılda yaklaşık 355 milyon lastik üretileceği tahmin edilmektedir (Scott, 2016). Artan talepleri karş1lamak için, otomobil endüstrisi lastik üretiminde hızlı bir artış göstermiştir. Bu lastikler, servis ömrünün bitiminden sonra açık depolama alanlarında saklanmaktadır (Adhikari vd., 2000). Dünya genelinde yılda yaklaşık olarak 1.5 milyar ton atık lastiğin açığa çıktığı tahmin edilmektedir (Mashiri vd., 2015). Bu kadar yüksek miktarda açığa çıkan atık lastiğin bertarafı için en kolay ve ucuz yöntem yakma işlemleridir. Ancak atık lastiklerin yakılarak bertaraf edilmesi hem yangin tehlikesini arttırmakta hem de çevreye büyük zarar vermektedir (Gesolu ve Güneyisi, 2011). Açık havada depolanan lastikler yağış sularını tutarak toprağa ulaşmasını engellemektedir. Ayrıca çeşitli böcekler için üreme alanları oluşturmaktadır (Dong vd., 2013). Bu yüzden atık lastiklerin ve diğer endüstriyel atıkların açık havada depolanması çevre ve insan sağlığı üzerinde olumsuz etkiler oluşturabilmektedir (Kaplan vd., 2020; Oikonomou ve Mavridou, 2009). Kâğıt veya cam gibi diğer ürünlerin aksine, yeni lastiklerin üretiminde geri dönüştürülmüşs lastiklerin kullanılması, güvenlik önlemleri nedeniyle çok uygun olmamaktadır. Ayrıca artan lastik talebi hammadde tüketimini de arttırmaktadır (PachecoTorres vd., 2018). Bu yüzden son y1llarda atık lastiklerin inşaat mühendisliği alanında agrega olarak kullanılması çevre ve insan sağlığı için olumlu bir etki yaratmaya başlamıştır (Gupta vd., 2017, 2015, 2014). Atık lastiklerin kırpılmış kauçuk formunda betona içerisinde agrega olarak kullanımına yönelik birçok çalışma mevcuttur. Atık lastiklerin agrega olarak betonda kullanılması tokluk ve durabilite gibi özellikleri iyileştirmiştir (Afshinnia ve Poursaee, 2015; Ganjian vd., 2009; Si vd., 2018). Ancak atık lastik agregalarının yüzeyindeki bazı sorunlardan dolayı aderansa bağlı olarak mekanik özellikler azalmaktadır. Bu yüzden atık lastik agregalarında $\mathrm{NaOH}$ gibi bazı kimyasal maddeler kullanılarak yüzey iyileştirme işleminin yapılmas1 önerilmektedir (Sofi, 2018). Yapılan bazı çalışmalarda atık lastik agregasından üretilen betonların taşıyıcı yap1 elemanlarında kullanılabileceğini belirtmiştir (Hassanli vd., 2017; Mendis vd., 2018). Günümüzde, atık lastiklerin çimento esaslı kompozitlerin içerisinde kullanılarak farklı alanlarda kullanılarak bertaraf edilmesi büyük hız kazanmıştır. Atık lastikler; darbe bariyerleri, asfalt ve beton kaplamaların tasarımında, oyun ve spor alanlarının zeminini gibi potansiyel kullanım alanlarına da sahiptir (Jiang vd., 2018). Yüksek hacimde atık lastik agregas1 kullanılması ile hafif betonların elde edilebileceği belirtilmiştir (Wakchaure ve Chavan, 2014).

Hafif beton, birim ağırlığ $2000 \mathrm{~kg} / \mathrm{m}^{3}$ altında olan ve genellikle hafif agregalar ile üretilen özel bir beton türüdür (Chandni ve Anand, 2018). Son yıllarda bir hafif beton türü olan köpük beton üzerine yapılan çalışmaların sayısı artış göstermektedir. Köpük beton, yapay hava kabarcıkları oluşturan köpük ajanı kullanılarak üretilen bir çimento harcı olarak tanımlanabilir. Birim ağırlığı $300-1800 \mathrm{~kg} / \mathrm{m}^{3}$ arasında değişen köpük beton birbirinden bağımsız hücresel boşluklardan oluşmaktadır (Amran vd., 2015). Köpük beton; minimum agrega tüketimi, yüksek akışkanlık, porozite ve $1 \mathrm{~s} 1$ yalıtımı, yangına dayanıklılık, düşük birim ağırlık ve yeterli basınç dayanımı gibi özelliklere sahiptir (Raj vd., 2019). Köpük beton hem yapısal hem de yapısal olmayan elemanların üretiminde kullanılmaktadır. Yalıtım amaçlı hafif blok üretimi, dolgu amaçlı kullanıldığı gibi prefabrik sektöründe de tercih edilen bir beton türüdür (Ghorbani vd., 2019; Tarasov vd., 2010). Köpük beton üretiminde kullanılan köpügün stabilitesi çok önemlidir. Stabilite açısından problemli olan köpük, betonda ayrışmaya ve birim ağırlık açısından homojen olmayan sonuçlara neden olur (Jones vd., 2016). Bununla birlikte köpük stabilitesini etkileyen birçok parametre olduğu için kontrolü oldukça zordur. Köpük ajanı türü ve dozajı, köpük üretim yöntemi, s/ç oranı ve agrega hacmi stabilite üzerinde etkili olan en önemli parametrelerdir (Ramamurthy vd., 2009). Karışım içerisinde kullanılan köpük içeriği betonun yoğunluğunu doğrudan etkilemektedir. Köpük içeriği arttıkça porozite artmakta ve buna bağlı olarak basınç dayanımı azalmaktadır. Örneğin: 28 günlük basınç dayanımı $43 \mathrm{MPa}$ 'dan $0.6 \mathrm{MPa}$ ya düştüğünde betonun yoğunluğu 1800 $\mathrm{kg} / \mathrm{m}^{3}$ 'den $280 \mathrm{~kg} / \mathrm{m}^{3}$ 'e düşmüşsür (Amran vd., 2015).

Köpük beton genellikle 1s1, ses ve yangın yalıtımı amacıyla kullanılmaktadır. Günümüzde daha çok yapisal olmayan elemanlar olan hafif blok üretimi için tercih edilmektedir. Bu yüzden köpük beton üretiminde agrega ve bağlayıcı olarak birçok endüstriyel atık kullanılmaktadır. Uçucu kül, taban külü, dökümhane cürufları, atık EPS'ler, atık lastikler ve geri dönüş agregaları köpük beton üretiminde kullanılan bazı endüstriyel atıklardır (Akhund vd., 2017; Bayraktar, 2020; Kim vd., 
2020; Lee ve Hung, 2005; Mehrani vd., 2019; Van Deijk, 1991).

$\mathrm{Bu}$ çalı̧̧mada, çevresel açıdan büyük sorunlar ortaya çıkaran atık lastiklerin köpük beton üretiminde agrega olarak değerlendirilmesi deneysel olarak incelenmiştir. Bu kapsamda farklı çimento tipleri kullanılarak farklı birim ağırlıklarda köpük betonlar üretilmiştir. Köpük betonların taze ve sertleşmiş özellikleri incelenmiştir.

\section{Malzeme ve yöntem}

\subsection{Malzemeler}

$\mathrm{Bu}$ çalışmada üretilen köpük betonlar için CEM II B/LL 32.5R, CEM III/A 32.5N, CEM IV B/(P-V) $32.5 \mathrm{R}$ tipi 3 farklı çimentolar kullanılmıştır.
Üretilecek köpük betonlar yapısal olmadığı için basınç dayanımları 42.5 olan çimentolar tercih edilmemiştir. Köpük betonların tasarımında $\mathrm{CO}_{2}$ emisyon değerleri ve maliyeti daha düşük olan kompoze çimentolar kullanılmıştır. Çimentoların kimyasal ve fiziksel özellikleri Tablo 1'de sunulmuştur.

Köpük betonlarda birim hacim ağırlık (BHA) değerlerini azaltmak için hafif agrega olarak sadece atık lastikler kullanılmıştır. Atık lastiklerin tane boyutu $0-1 \mathrm{~mm}$, tane yoğunluğu (doygun kuru yüzey) $0.90 \pm 5 \mathrm{~g} / \mathrm{cm}^{3}$ 'tür. Atık lastiklerin su emme değeri ise $\% 1.40$ olarak belirlenmiştir. Atık lastiklerin kimyasal özellikleri Tablo 2'de verilmiştir. Atık lastik ve çimentoların genel görünümü Şekil 1'de sunulmuştur.

Tablo 1. Çimentoların kimyasal ve fiziksel özellikleri

\begin{tabular}{cccc}
\hline Oksit (\%) & CEM II B/LL 32.5R & CEM III/A 32.5N & CEM IV B/(P-V) 32.5 R \\
\hline $\mathrm{CaO}$ & 60.2 & 48.7 & 41.2 \\
\hline $\mathrm{SiO}_{2}$ & 19.9 & 31.2 & 36.3 \\
\hline $\mathrm{Al}_{2} \mathrm{O}_{3}$ & 2.9 & 9.4 & 9.9 \\
\hline $\mathrm{Fe}_{2} \mathrm{O}_{3}$ & 4.0 & 2.3 & 5.4 \\
\hline $\mathrm{MgO}$ & 1.7 & 3.9 & 1.4 \\
\hline $\mathrm{K}_{2} \mathrm{O}$ & 0.8 & 0.6 & 0.4 \\
\hline $\mathrm{Na}_{2} \mathrm{O}$ & 0.3 & 0.4 & 0.3 \\
\hline $\mathrm{SO}_{3}$ & 2.5 & 1.5 & 2.1 \\
\hline $\mathrm{LOI}$ & 7.5 & 1.2 & 2.5 \\
\hline & & Fiziksel Özellikler & 2.66 \\
\hline Özgül Ağırlık & 2.95 & 2.96 & 5100 \\
\hline $\begin{array}{c}\text { Özgül Yüzey Alanı } \\
\left(\mathrm{cm}^{2} / \mathrm{g}\right)\end{array}$ & 3900 & 3400 & \\
\hline
\end{tabular}

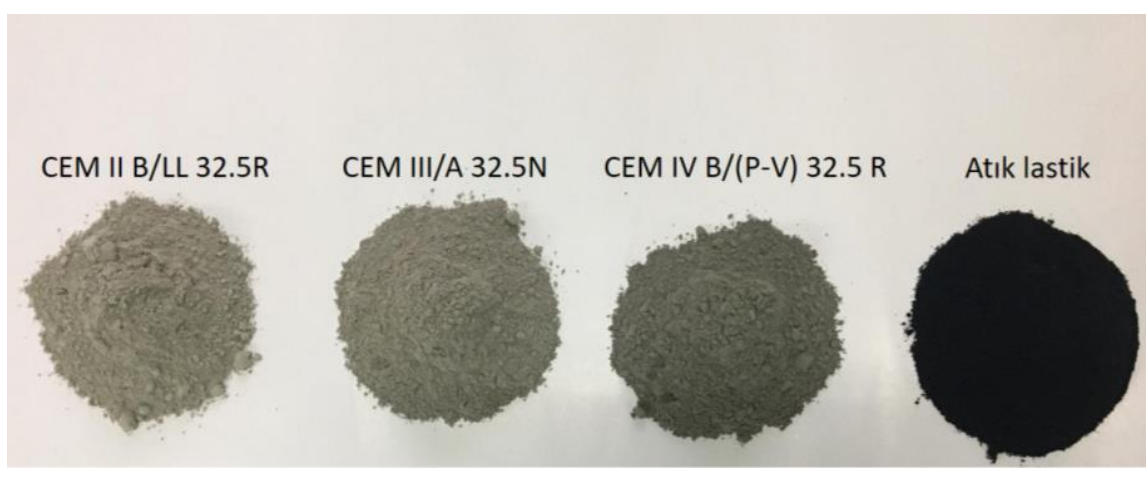

Şekil 1. Malzemelerin genel görünümü

Tablo 2. Atık lastiklerin kimyasal özellikleri (Elementel Analizi)

\begin{tabular}{ccccccc}
\hline Element & $\mathrm{C}$ & $\mathrm{Zn}$ & $\mathrm{O}$ & $\mathrm{S}$ & $\mathrm{H}$ & $\mathrm{Na}$ \\
\hline$\%$ & 93.2 & 2.2 & 1.9 & 1.6 & 0.8 & 0.3 \\
\hline
\end{tabular}

Karışımların hazırlanmasında kullanılan köpük ajanına ait teknik özellikler Tablo 3'de verilmiştir. Köpük ajanı kullanılarak üretilen köpügün yoğunluğu $120 \pm 10 \quad \mathrm{~g} / 1$ olarak belirlenmiştir.
Karışımların hazırlanmasında ve kür işleminde içilebilir nitelikte olan Kastamonu şebeke suyu kullanılmışırır. 
Tablo 3. Köpük ajanına ait teknik özellikler

\begin{tabular}{ccc}
\hline Kimyasal bileşim & \multicolumn{3}{c}{ Sentetik sıvı (Hava sürükleyici esasli) } \\
\hline Görünüm (Renk) & \multicolumn{2}{c}{ Açık kahverengi } \\
\hline Yoğunluk & $1.03 \pm 0.02 \mathrm{~kg} / \mathrm{l}$ & ISO 758 \\
\hline $\mathrm{pH}$ & $5.0 \pm 1$ & TS 6365 EN 1262 \\
\hline Klor içeriği $(\mathrm{Cl})$ & $<\% 0.1$ & TS EN 480-10 \\
\hline Alkali içeriği & $<\% 5$ & TS EN 480-12 \\
\hline Donma noktası & $-5^{\circ} \mathrm{C}$ &
\end{tabular}

\subsection{Deneysel yöntemler}

Köpük betonlarda çimento dozajı ve s/ç oranı tüm karışımlarda sabittir. Çimento dozaj $1300 \mathrm{~kg} / \mathrm{m}^{3}$, s/ç oranı ise 0.75 olarak seçilmiştir. Karışımlarda 3 farklı çimento tipi ve köpük içeriği kullanılarak toplam 9 karışım üretilmiştir. Karışım oranları ve malzeme miktarları Tablo 4'de verilmiştir.

Tablo 4. Köpük betonlara ait malzeme miktarları

\begin{tabular}{|c|c|c|c|c|c|c|}
\hline Karışım No. & \multicolumn{2}{|c|}{ Karışım özellikleri } & \multicolumn{4}{|c|}{ Malzeme miktarları $\left(\mathrm{kg} / \mathrm{m}^{3}\right)$} \\
\hline & Çimento tipi & Köpük İçeriği $\left(\mathrm{kg} / \mathrm{m}^{3}\right)$ & Çimento & Atık lastik agregası & $\mathrm{Su}$ & Köpük \\
\hline 1 & CEM II & \multirow[t]{3}{*}{ 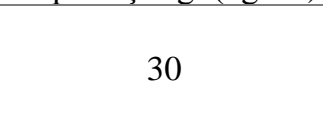 } & 300 & 304.0 & 225 & 30 \\
\hline 2 & CEM III & & 300 & 304.2 & 225 & 30 \\
\hline 3 & CEM IV & & 300 & 297.3 & 225 & 30 \\
\hline 4 & CEM II & \multirow{3}{*}{60} & 300 & 204.0 & 225 & 60 \\
\hline 5 & CEM III & & 300 & 204.2 & 225 & 60 \\
\hline 6 & CEM IV & & 300 & 197.3 & 225 & 60 \\
\hline 7 & CEM II & \multirow{3}{*}{90} & 300 & 104.0 & 225 & 90 \\
\hline 8 & CEM III & & 300 & 104.2 & 225 & 90 \\
\hline 9 & CEM IV & & 300 & 97.3 & 225 & 90 \\
\hline
\end{tabular}

Tablo 4'de yer alan karışımlar Hobart tipi mikser ile hazırlanmıştır. Karışımlar üzerinde ilk olarak ASTM C 1437'ye (ASTM C1437, 2013) uygun olarak yayılma çapları belirlenmiştir. Köpük betonlar 24 saat sonra kalıplarından sökülerek deney gününe kadar standart kür işlemine başlanılmıştır. Karışımlar üzerinde 7 ve 28 . günlerde eğilme (3 noktalı) ve basınç dayanımları gerçekleştirilerek mekanik özellikleri belirlenmiştir. Eğilme dayanımı deneyi ASTM C 348 (ASTM C348, 1998) standardına uygun olarak $40 * 40 * 160 \mathrm{~mm}^{3}$ boyutlu numunelerde gerçekleştirilmiştir. Eğilme dayanımı belirlendikten sonra ASTM C 349'a (ASTM C349, 2002) göre basınç dayanımı deneyi gerçekleştirilmiştir. Köpük betonların fiziksel özellikleri ASTM C 642 (ASTM C642-13, 2013) standardına göre belirlenmiştir. Fiziksel özellikler 28. günde $50 * 50 * 50 \mathrm{~mm}^{3}$ ayritlı küp numunelerde belirlenmiştir. Köpük betonların kılcal yolla emdikleri su miktarı ASTM C 1585 (ASTM C 1585-04, 2004) standardına göre tespit edilmiştir. Kapilarite deneyi 28 günlük köpük betonlarda ve $50 * 50 * 50 \mathrm{~mm}^{3}$ boyutlarındaki küp numunelerde gerçekleştirilmiştir. Kapilarite deneyi su işleme derinliğinin belirlenmesi için ilk 24 saatlik zaman aralığında yapılmıştır.

\section{Bulgular ve tartışma}

\subsection{Köpük betonların taze hal özellikleri}

Şekil 2'de köpük betonların çimento tipi ve köpük içeriğine bağlı olarak yayılma çaplarındaki değişim görülmektedir. Köpük içeriği arttıkça betonların yayılma çapları artmaktadır. CEM II tipi çimento kullanılan köpük betonların yayılma çapları 13-16 $\mathrm{cm}$ arasında değişmektedir. CEM III tipi çimento kullanılan köpük betonlarda köpük içeriği arttıkça yayılma nispeten daha çok artı̧̧ göstermektedir. Köpük içeriğinin $90 \mathrm{~kg} / \mathrm{m}^{3}$ olması durumunda yayılma çapı \%138.9 oranında artış göstermiştir. CEM IV çimentosunda bu oran \%95.2 olarak belirlenmiştir. CEM II çimentosundaki köpük içeriğinin artması yayılma çapını çok etkilememiştir. CEM III ve CEM IV çimentolarının yayılma çapını daha çok arttırmasının nedeni pasta hacmi ile ilişkilidir. CEM III ve CEM IV çimentoları CEM II çimentosuna göre Pasta hacmini daha çok arttırdığı için köpük betonların işlenebilirliği de artmıştır. Köpük içerisinde yer alan hava kabarcıkları da pasta bünyesine girdiğinde yine hacim artışına yol açtığ 1 için işlenebilirlik artmaktadır. Yayılma çapı açısından CEM III ve IV tipi çimentolarda 60 ve 90 $\mathrm{kg} / \mathrm{m}^{3}$ köpük içeriği kullanmak daha uygun olmaktadır. 


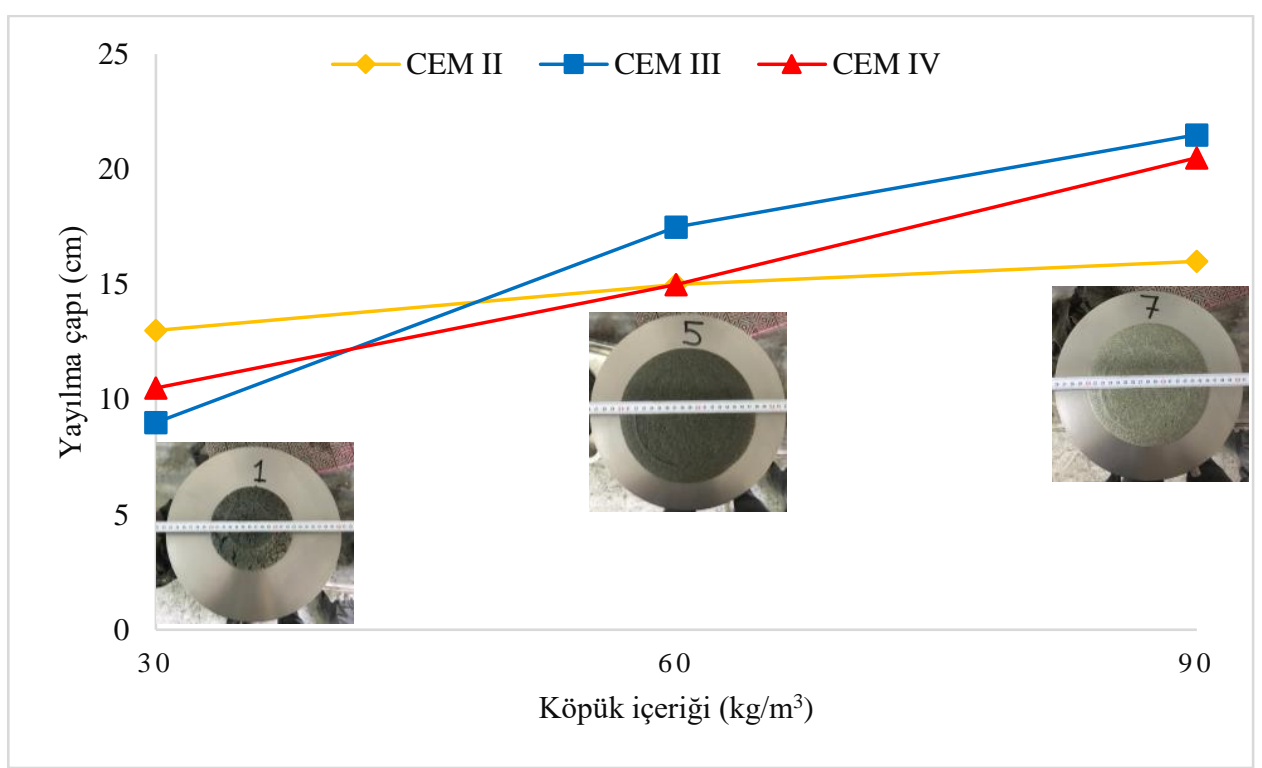

Şekil 2. Köpük betonların yayılma çapları

Köpük betonun işlenebilirliği, viskoziteyi kontrol ederek görsel olarak değerlendirilebilir. Geleneksel betonda yaygın olarak kullanılan slump (çökme) testi düşük yoğunluklu köpük betonlar için uygun değildir (British Standard Institution, 2009). Köpük hacmi arttığında, karışımlar daha sert hale gelir ve işlenebilirliği korumak için daha yüksek su içeriğine ihtiyaç duyarlar (Krishnan ve Anand, 2018). Ayrıca köpük betonların taze birim hacim (BHA) ağırlı̆̆ 1 azaldığında köpük betonun kendi kendine yayılma kabiliyeti de azalır, bu durum karışımdaki su ihtiyacını arttırmaktadır (Gowri ve Anand, 2018). Chen ve Li tarafindan yapilan çalışmada karışım içerisindeki köpük hacmi arttıkça yayılma çapları artış göstermiştir. Köpüğün içindeki küresel kabarcıklar "bilyalı rulman" etkisi yaratarak karışımların işlenebilirliğini arttırdığı belirtilmiştir (Chen ve Liu, 2013).

\subsection{Köpük betonların fiziksel özellikleri}

Şekil 3'de köpük betonların görünür porozite, su emme ve kuru BHA özellikleri verilmiştir. Sütun grafikler görünür porozite ve su emme değerlerini (Sol düşey eksen), Daire simgeler ise köpük betonların kuru BHA değerlerini (sağ dikey eksen) vermektedir.

Karışımlardaki köpük içeriği arttıkça köpük betonların görünür porozite ve su emme değerleri artmaktadır. Köpük içeriği $30 \mathrm{~kg} / \mathrm{m}^{3}$ olan betonların görünür porozite değerleri \%21.2-27.9 arasında değişirken, köpük içeriği $90 \mathrm{~kg} / \mathrm{m}^{3}$ olduğunda görünür porozite değerleri \%58.5-60 arasında değişmektedir. Köpük içeriğinin $90 \mathrm{~kg} / \mathrm{m}^{3}$ olması halinde çimento tipinin görünür porozite üzerinde çok önemli bir etkisi bulunmaktadır. 30 ve $60 \mathrm{~kg} / \mathrm{m}^{3}$ köpük içeriğinde CEM III tipi çimentodan üretilen köpük betonların görünür porozite değerleri nispeten daha yüksek olmaktadır. $\mathrm{Bu}$ durum CEM III üretiminde kullanılan YFC'nin gözenekliliğinden kaynaklanabilmektedir.

Köpük içeriği arttıkça betonların su emme değerleri artış göstermektedir. CEM IV çimentosundan üretilen köpük betonlarda köpük içeriğinin $30 \mathrm{~kg} / \mathrm{m}^{3}$ den $60 \mathrm{~kg} / \mathrm{m}^{3}$ e çıkarılması durumunda su emme değeri yaklaşık \%18.8 oranında artmıştır. Köpük içeriği $90 \mathrm{~kg} / \mathrm{m}^{3}$ olduğunda ise su emme oranı \%116.6 artmıştır. 30 $\mathrm{kg} / \mathrm{m}^{3}$ köpük içeriğine sahip köpük betonların su emme değerleri \%20'nin altında iken $90 \mathrm{~kg} / \mathrm{m}^{3}$ köpük içeriğine sahip köpük betonların su emme değeri \%30'dan fazla olmaktadır. CEM II çimentosundan üretilen köpük betonların su emme ve görünür porozite değerleri genellikle diğer çimento tiplerine göre daha azdır.

Şekil 2'de görüldüğü gibi çimento tipinin kuru BHA üzerinde çok etkisi görülmemiştir. Köpük içeriği $30 \mathrm{~kg} / \mathrm{m}^{3}$ olan karışımların BHA değerleri $920-980 \mathrm{~kg} / \mathrm{m}^{3}$ arasında değişmektedir. BHA değerleri, $60 \mathrm{~kg} / \mathrm{m}^{3}$ köpük içeriğinde 660-730, 90 $\mathrm{kg} / \mathrm{m}^{3}$ köpük içeriğinde ise $590-640 \mathrm{~kg} / \mathrm{m}^{3}$ arasında değişmektedir. Köpük içeriği arttıkça betonların içerisindeki hava kabarcığı oranı artmakta ve bunun sonucunda görünür porozite artmaktadır. Görünür porozitenin artması BHA değerlerini azaltırken su emme değerlerini arttırmaktadır. 


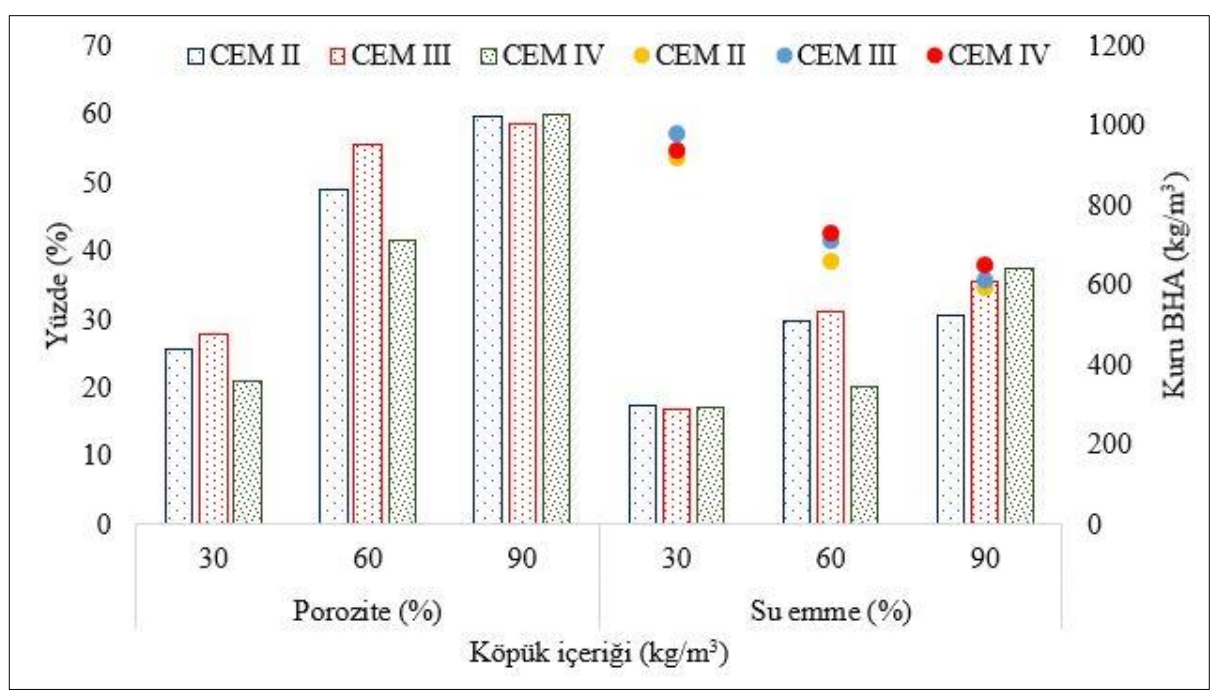

Şekil 3. Köpük betonların fiziksel özellikleri (Sütün grafikler: Yüzde- Simgeler: Kuru BHA)

Chen ve Li, köpük hacmi arttıkça karışımların BHA değerlerinin azaldığını belirtmiştir (Chen ve Liu, 2013). Liv d. Tarafından yapılan çalışmada da köpük içeriği arttıkça karışımların görünür porozite değerleri artmış ve 1sıl iletkenlik katsayıları azalmıştır (Li vd., 2019). Benzer sonuçlar Ahmed ve Chen tarafından yapılan çalışmada da gözlenmiştir (Ahmad ve Chen, 2019).

\subsection{Köpük betonların mekanik özellikleri}

Köpük betonların 7 ve 28. günlerdeki basınç ve eğilme dayanımları Şekil 4'de sunulmuştur. Köpük betonlarda 7. günde geçekleştirilen üç noktalı eğilme dayanım gözlenememiştir. 28 günlük köpük betonlarda eğilme dayanımı 0.1-0.4 MPa arasında elde edilmiştir. Köpük içeriği arttıkça betonların eğilme dayanımları azalmaktadır. CEM IV tipi çimentolardan üretilen betonların daha yüksek eğilme dayanımına sahip olduğu gözlenmiştir. CEM IV tipi çimentolardan üretilen köpük betonların görünür porozite değerleri daha düşük olduğu için eğilme dayanımları daha yüksektir. Görünür porozite değeri nispeten daha yüksek olan CEM II tipi çimentosundan üretilen köpük betonların eğilme dayanımı $0.24-0.10 \mathrm{MPa}$ arasında değişmektedir. Köpük betonların 7 günlük basınç dayanımları 0.62-0.16 $\mathrm{MPa}, 28$ günlük basınç dayanımları ise 0.63-1.55 $\mathrm{MPa}$ arasında değişmektedir. Köpük içeriğindeki artış hem 7 hem de 28 günlük basınç dayanımlarını azaltmıştır. Çimento tipleri açısından CEM III tipi çimento kullanımı genellikle basınç dayanımlarını daha çok arttırmaktadır. Kompoze çimentolarda kullanılan mineral katkılar puzolanik ya da filler etki göstererek dayanıma katkı sağlamaktadır. CEM III tipi çimentolarda kullanılan YFC kendi başına bağlayıcı olduğu için hidrolik özellikleri nispeten daha fazladır. Bu yüzden köpük beton üretiminde
CEM II ve CEM IV çimentolarına göre daha yüksek basınç dayanımları elde edilmiştir. 7 günlük basınç dayanımlarında CEM II ve CEM IV çimentolarının benzer özellik gösterdiği görülmektedir. 28. günde köpük içeriği arttıkça CEM III tipi çimento kullanımı daha uygun olmaktadır. CEM III tipi çimentonun özgül yüzey alanı fazla olduğu için işlenebilirlik problemlerine yol açabilmektedir. $\mathrm{Bu}$ yüzden CEM III tipi çimentolardan üretilen köpük betonlarda köpük içeriğinin artması işlenebilirlik açısından önem kazanmaktadır. CEM III ile üretilen köpük betonlarda işlenebilirlik artışı için köpük içeriği arttırılmalıdır. $90 \mathrm{~kg} / \mathrm{m}^{3}$ köpük içeriğinde CEM II çimentosu yerine CEM III çimentosu kullanılması durumunda 28 günlük basınç dayanımı \%41.6 artmaktadır. $30 \mathrm{~kg} / \mathrm{m}^{3}$ köpük içeriğinde ise CEM IV çimentosu kullanımı 28 günlük basınç dayanımını \%28.1 arttırmıştır. CEM III tipi çimentonun atık lastik içerikli köpük betonlarda kullanımı daha uygun olmaktadır. Ayrıca YFC'nin pasta-agrega ara yüzeyini iyileştirdiğini gösteren birçok çalışma bulunmaktadır (Gao et al., 2005; Majhi and Nayak, 2020). Bu çalışmada da CEM III içerisinde yer alan YFC'nin pasta ve agrega arasındaki aderansı arttırdığ düşünülmektedir. CEM IV tipi çimentolarda puzolanik aktivite gelişimi tamamlanmadığı için basınç dayanımları daha düşük değerler almıştır.

Nambiar ve Ramamurthy tarafindan yapilan çalışmada köpük içeriği arttıkça karışımların BHA değerleri azalmış ve buna bağlı olarak da basınç dayanımları azalmıştır. Köpük beton üretiminde görünür porozitenin basınç dayanımı üzerinde doğrudan etkili olduğu vurgulanmıştır (Nambiar ve Ramamurthy, 2006). Eltayeb vd., \%30'a kadar atık lastikleri ince agrega yerine kullanarak farkl1 yoğunluklarda köpük betonlar üretmişlerdir. Atık 
lastik içeriği arttıkça köpük betonların basınç dayanımının azaldığı gözlenmiştir (Eltayeb vd., 2020). Khan vd. yaptıkları çalışmada kuru BHA ve dayanım arasında $\mathrm{R}^{2}=0.72$ değeri ile korelasyon elde etmiştir. Köpük betonların BHA değerleri arttıkça basınç dayanımları da artı̧̧ göstermektedir (Khan vd., 2019).

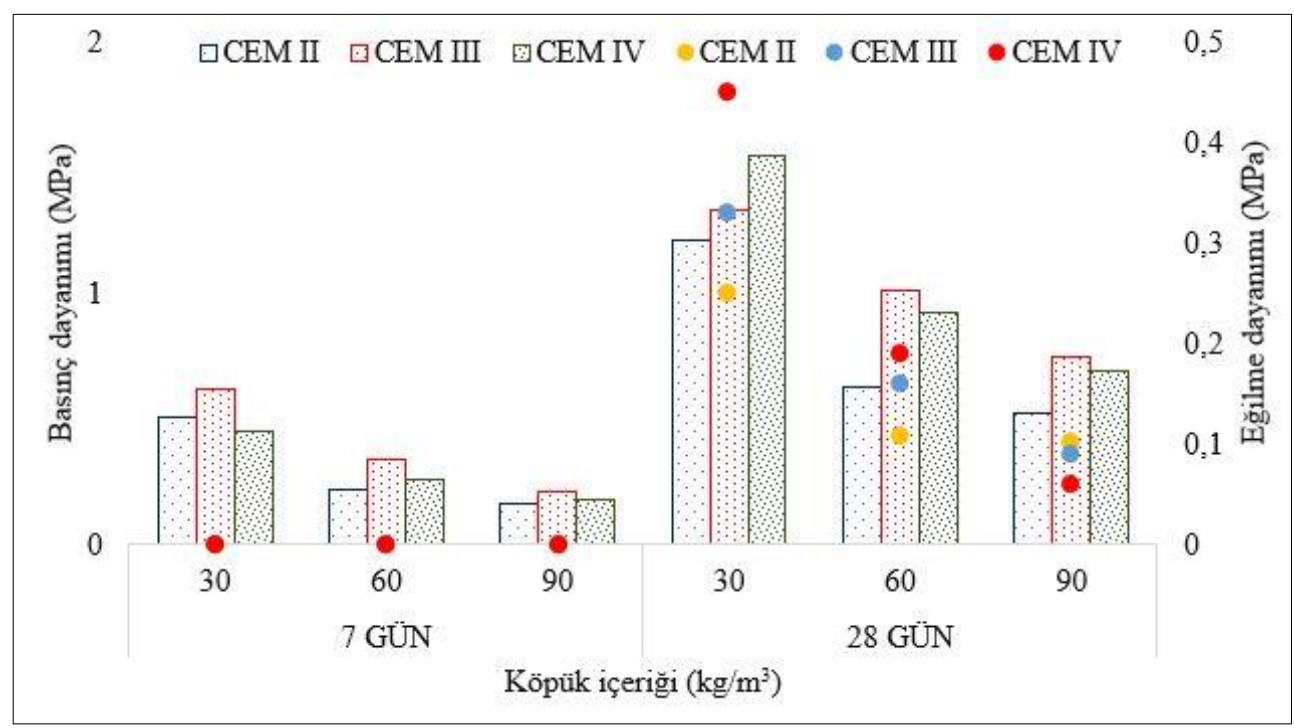

Şekil 4. Köpük betonların mekanik özellikleri (Sütün grafikler: Basınç dayanımı - Simgeler: Eğilme dayanımı)

\subsection{Köpük betonların kapilarite özellikleri}

Şekil 5'de 24 saat boyunca gerçekleştirilen kapilarite deneyi için su işleme derinlikleri verilmiştir. Şekilde görüldüğü gibi köpük içeriği arttıkça su işleme derinlikleri azalmaktadır. 90 $\mathrm{kg} / \mathrm{m}^{3}$ köpük içeriğine sahip betonların su işleme derinlikleri 2.6-3.3 mm arasında değişmektedir. $\mathrm{Su}$ işleme derinliği $60 \mathrm{~kg} / \mathrm{m}^{3}$ köpük içeriğinde 4.1-5.4, $30 \mathrm{~kg} / \mathrm{m}^{3}$ köpük içeriğinde ise $6.2-8.2 \mathrm{~mm}$ arasında değişmektedir. $90 \mathrm{~kg} / \mathrm{m}^{3}$ köpük içeriğinde CEM II çimentosu su işleme derinliğini CEM IV çimentosuna göre \%25.8 oranında azaltmıştır. $\mathrm{Bu}$ oran $30 \mathrm{~kg} / \mathrm{m}^{3}$ köpük içeriğinde $\% 31.3$ olarak belirlenmiş̧ir. CEM IV çimentosundan üretilen köpük betonların su işleme derinlikleri genellikle daha fazladır. Su işleme derinlikleri açısından çimento tipleri CEM IV $>$ CEM III $>$ CEM II olarak sınıflandırılmıştır. Köpük içeriği arttıkça kılcal yolla emilen su miktarı azalmaktadır. Köpük içerisinde yer alan yapay hava kabarcıkları kılcal boşluklar ile bağlantıyı azalttığı için su emme oranı azalmaktadır. Köpük içeriği betonların görünür porozitesini arttırmakta ancak su işleme derinliğini azaltmaktadır. Hava kabarcıklarının birbirinden bağımsız olması bu özelliği ön plana çıkarmaktadır.

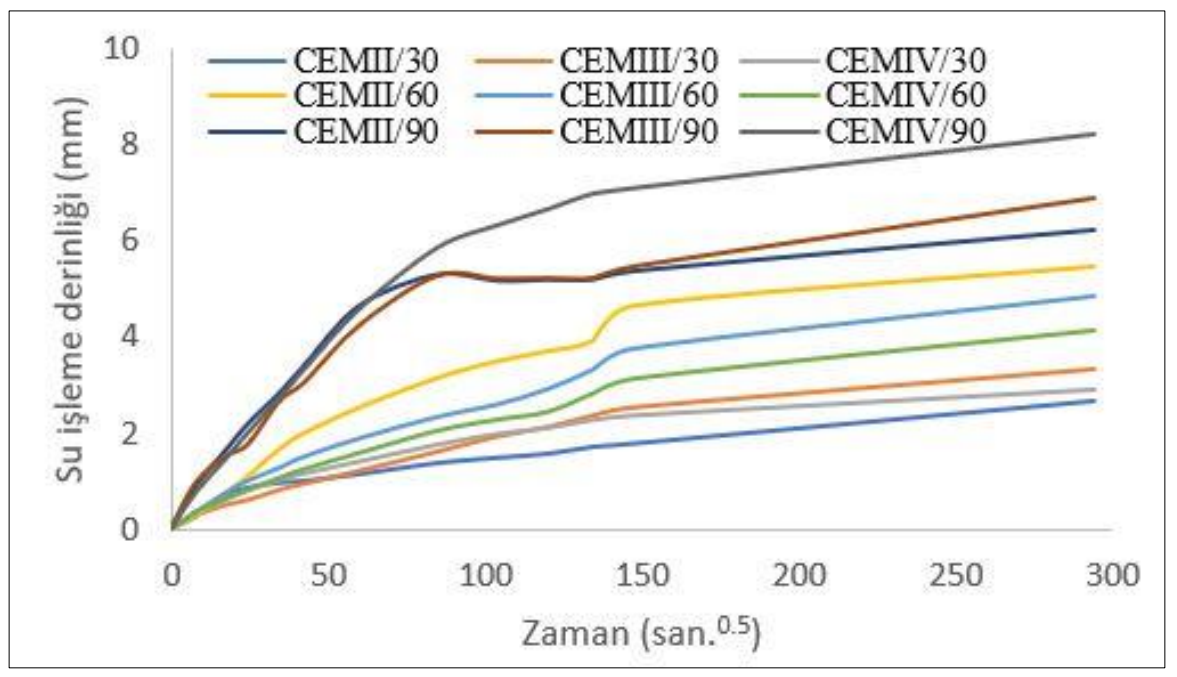

Şekil 5. Köpük betonların zamana bağlı su işleme derinlikleri 
Prim ve Wittmann gazbetonların kapilarite özelliklerini deneysel olarak incelemiştir. Gaz betonların kılcal yolla su emme özelliklerinin gözenek yapısı ile ilgili olduğunu belirlenmiştir. Yapay hava gözenekleri arttıç̧a gaz betonların kılcallık katsayıları azalmıştır (Prim ve Wittmann, 1983). Ayrıca literatürde köpük hacmi arttıkça kılcal yolla su emiliminin azaldığını belirten çalışmalar mevcuttur (Giannakou ve Jones, 2002; Nambiar ve Ramamurthy, 2007). Madjoudj vd. köpük betonların yoğunluğu azaldıkça kılcal yolla emilen su miktarının azaldığını belirtmiştir (Giannakou ve Jones, 2002).

\subsection{Köpük betonların termal özellikleri}

Literatürde köpük betonların termal özelliklerini inceleyen birçok çalışma yer almaktadır. Çalışmalarda termal özelliklerden olan 1sıl iletkenlik katsayısı $(\lambda)$ dikkate alınmıştır. Pan vd. tarafından yapılan çalışmada köpük betonların basınç dayanımları $0.33-1.10 \mathrm{MPa}, \lambda$ değeri ise 0.05-0.07 W/mK arasında değişmektedir (Pan vd., 2014). Jiang vd. 0.25-0.74 MPa basınç dayanımı aralığ 1 için yaklaşık $0.050 \mathrm{~W} / \mathrm{Mk} \quad \lambda$ değeri ölçmüştür (Jiang vd., 2016). Kılınçarslan vd tarafindan yapılan çalışmada kuru BHA değeri 600 $\mathrm{kg} / \mathrm{m}^{3}$ olan köpük betonların $\lambda$ değeri 0.14-0.16 $\mathrm{W} / \mathrm{mK}$ arasında değişmektedir (Kilincarslan vd., 2018). Li vd. Tarafından yapılan çalışmada BHA değerleri $250-700 \mathrm{~kg} / \mathrm{m}^{3}$ arasında değişen köpük betonlar üretilmiştir. Köpük betonların $\lambda$ değeri 0.070-0.164 arasında değişmektedir (Li vd., 2019). Wei vd. tarafından üretilen köpük betonların görünür poroziteleri $0.11-0.84$ arasında değişirken $\lambda$ değeri $0.08-0.43 \mathrm{~W} / \mathrm{mK}$ arasında değişmektedir (Wei vd., 2013).

$\mathrm{Bu}$ çalışmada atık lastiklerden üretilen köpük betonların $\lambda$ değeri deneysel olarak belirlenememiştir. Üretilen köpük betonların BHA ve basınç dayanımı değerleri Kılınçarslan vd. (Kilincarslan vd., 2018) ve Li vd. (Livd., 2019) tarafindan üretilen köpük betonlara benzerlik göstermektedir. Bu çalışmalarda BHA ile $\lambda$ değeri arasında önerilen amprik formüller kullanılarak atık lastik içerikli köpük betonların termal özellikleri yaklaşık olarak (tahmini) belirlenmiştir. Tablo 5'te atık lastikli köpük betonların yaklaşık $\lambda$ değeri diğer yapı malzemeleri ile karşılaştırılmalı olarak verilmiştir. Tablo 5 'te yer alan $\lambda$ değerleri malzemelerin yoğunluklarına göre değişkenlik göstermektedir.

Tablo 5. Bazı yapı malzemelerinin 1sıl iletkenlik katsayıları

\begin{tabular}{|c|c|c|}
\hline Yap1 Malzemesi & Yöntem & $\lambda(\mathrm{W} / \mathrm{mK})$ \\
\hline Bu çalışma & $\mathrm{Li}$ & $0.14-0.22$ \\
\hline (Atık lastikli köpük betonlar) & Kılınçarslan & $0.15-0.20$ \\
\hline Düşey delikli tuğla (EN 771-3, 2003) & \multirow{6}{*}{ Deneysel } & $0.50-1.40$ \\
\hline Yatay delikli tuğla (EN 771-3, 2003) & & $0.18-0.45$ \\
\hline Gazbeton (EN 771-3, 2003) & & $0.09-0.29$ \\
\hline Bims blok (EN 771-3, 2003) & & $0.28-0.74$ \\
\hline XPS (Vo vd., 2011) & & $0.030-0.040$ \\
\hline EPS (Vo vd., 2011) & & $0.035-0.040$ \\
\hline
\end{tabular}

\section{6. İstatistiksel analiz}

Deneysel sonuçlara bağlı olarak gruplar arasındaki farklılığın belirlenebilmesi için iki yönlü varyans analizi (ANOVA) kullanılmıştır. ANOVA analizi ile çimento tipi ve köpük içeriğinin köpük beton özellikleri üzerindeki etkileri belirlenmiştir. ANOVA analizi; yayılma çap1, görünür porozite, su emme, kuru BHA, 28 günlük basınç dayanımı ve su işleme derinlikleri için gerçekleştirilmiştir. İki yönlü ANOVA analizine ait sonuçlar Tablo 6 'da verilmiştir.
Tablo 6'da görüldüğü gibi çimento tipi köpük beton özellikleri üzerinde etkili değildir. Ancak köpük içeriğinin değişmesi köpük betonun özelliklerini oldukça etkilemektedir. Hafif blok üretiminde kullanılan köpük betonda kompoze çimento tipinin çok önemli olmayacağ 1 belirlenmiştir. Çünkü çimento tipine bağlı $\alpha$ değerleri 0.05 değerinden büyüktür. Ancak köpük içeriğindeki değişim fiziksel ve mekanik özellikleri değiştirmektedir. Köpük içeriğine bağlı $\alpha$ değerleri 0.05 değerinden küçüktür. $\mathrm{Bu}$ yüzden yapısal olmayan köpük beton tasarımında köpük içeriğine daha çok dikkat edilmelidir. 
Tablo 6. İki yönlü varyans analizi (ANOVA) sonuçları

\begin{tabular}{ccccccccc}
\hline & \multicolumn{8}{c}{ İki Yönlü ANOVA $(\alpha=0.05)$} \\
\cline { 2 - 9 } Köpük beton özellikleri & \multicolumn{9}{c}{ Değişkenler } \\
\cline { 2 - 9 } & $\alpha$ & F & Etki $(\%)$ & Anlamlılık & $\alpha$ & F & Etki $(\%)$ & Anlamlı̈lı içeriŏi $\left(\mathrm{kg} / \mathrm{m}^{3}\right)$ \\
\cline { 2 - 9 } & 0.833 & 0.20 & 2.4 & Hayır & 0.043 & 8.16 & 97.6 & Evet \\
\hline Yayılma çapı & 0.610 & 0.56 & 3.6 & Hayır & 0.011 & 14.96 & 96.4 & Evet \\
\hline Görünür porozite & 0.731 & 0.34 & 2.9 & Hayır & 0.024 & 11.26 & 97.1 & Evet \\
\hline Su emme & 0.229 & 2.30 & 5.1 & Hayır & 0.002 & 42.96 & 94.9 & Evet \\
\hline Kuru BHA & 0.134 & 3.48 & 7.8 & Hayır & 0.002 & 41.29 & 92.2 & Evet \\
\hline $\begin{array}{c}\text { Basınç dayanımı } \\
\text { (28 gün) }\end{array}$ & 0.902 & 0.11 & 0.9 & Hayır & 0.012 & 17.78 & 99.1 & Evet \\
\hline Su işleme derinliği
\end{tabular}

\section{Sonuçlar}

Köpük betonların üretimindeki köpük hacmi arttıkça yayılma çapları artmaktadır. Köpük içeriğinin $60 \mathrm{~kg} / \mathrm{m}^{3}$ ve üzeri olması durumunda yayılma çapları $15 \mathrm{~cm}$ 'den fazla olmaktadır. CEM III tipi çimentodan üretilen köpük betonların işlenebilirlikleri daha uygun olmaktadır. CEM II ve CEM IV çimentolarının Blaine değerlerinin yükssek olması işlenebilirliği nispeten azaltmıştır.

60 ve $90 \mathrm{~kg} / \mathrm{m}^{3}$ köpük içeriğinde görünür porozite değerleri \%50'den fazladır. Köpük içeriği arttıkça yapay hava kabarciklarını sayısı artmakta buna bağlı olarak ta boşluk oranı artmaktadır. CEM IV çimentosundan üretilen köpük betonların görünür porozite değerleri daha düşük değerler almıştır. $\mathrm{Bu}$ durum çimentonun Blaine değerinin yüksek olması ile ilişkilidir. Köpük betonların görünür porozite değerleri arttıkça su emme değerleri de artış göstermektedir.

Köpük betonların BHA değerleri $595-980 \mathrm{~kg} / \mathrm{m}^{3}$ arasında değişmektedir. Köpük içeriği arttıkça betonların BHA değerleri azalmaktadır. $90 \mathrm{~kg} / \mathrm{m}^{3}$ köpük içeriğine sahip betonların BHA değerleri $645 \mathrm{~kg} / \mathrm{m}^{3}$ değerinin altındadır. CEM IV tipi çimentolar görünür porozite değerini azalttığı için BHA değerlerini de nispeten arttırmıştır.

Köpük içeriğindeki artış köpük betonların mekanik özelliklerini azaltmaktadır. $30 \mathrm{~kg} / \mathrm{m}^{3}$ köpük içeriğine sahip köpük betonların 28 günlük basınç dayanımları 1.3-1.5 $\mathrm{MPa}$ arasında değişirken 90 $\mathrm{kg} / \mathrm{m}^{3}$ içeriğinde bu aralık $0.53-0.75 \mathrm{MPa}$ arasında olmaktadır. Köpük betonların basınç dayanımları arttıkça 28 günlük eğilme dayanımları da artış göstermektedir. CEM III çimentosundan üretilen köpük betonlarda daha yüksek basınç dayanımları gözlenmiştir. $\mathrm{Bu}$ durum CEM III üretiminde kullanılan YFC ile açıklanabilmektedir. CEM II üretiminde kullanılan kalker sadece dolgu (filler) görevi yapmaktadır. CEM IV bünyesinde yer alan puzolanik malzemeler ise 28 günlük basınç dayanımına etki edememiştir. YFC ise kendi başına bağlayıcılık gösterebilmesi ve bu malzemelere göre daha yüksek hidrolik özellikleri olması nedeniyle basınç dayanımını nispeten arttırmıştır.

Köpük içeriğindeki artış köpük betonlardaki su işleme derinliğini azaltmıştır. Birbirinden bağımsız olan yapay hava kabarcıkları k1lcal yolla emilen su miktarını azaltabilmektedir. Çimento tipleri arasında ise su işleme derinliği açısından belirgin bir fark gözlenmemiştir.

İstatistiksel analiz sonucunda; çimento tipindeki değişim atık lastiklerden üretilen köpük betonların taze ve sertleşmiş özelliklerini etkilememektedir. Ancak köpük içeriğindeki değişim köpük beton özelliklerini doğrudan etkileyen bir faktördür. Köpük beton üretiminde kompoze çimentoların kullanımı hem maliyeti azaltacak hem de $\mathrm{CO}_{2}$ emisyonlarını azaltacaktır.

Sonuç olarak, agrega yerine atık lastiklerden üretilen köpük betonlara ait deneysel verilerin literatürdeki diğer köpük betonlara yakın olduğu gözlenmiştir. Köpük beton üretiminde atık lastik agregası kullanılarak gaz betona yakın bir blok eleman üretme imkanının olduğu belirlenmiştir.

\section{Kaynaklar}

Adhikari, B., De, D. and Maiti, S., (2000). Reclamation and recycling of waste rubber. Progress in Polymer Science, 25, 909-948. https://doi.org/10.1016/S0079-6700(00)00020-4

Afshinnia, K. and Poursaee, A., (2015). The influence of waste crumb rubber in reducing the alkali-silica reaction in mortar bars. Journal of Building Engineering, 4, 231-236. https://doi.org/10.1016/j.jobe.2015.10.002

Ahmad, M.R. and Chen, B., (2019). Experimental research on the performance of lightweight concrete containing foam and expanded clay 
aggregate. Composites Part B Engineering 171, 46-60.

https://doi.org/10.1016/j.compositesb.2019.04.0 25

Akhund, M.A., Khoso, A.R., Pathan, A.A., Memon, U. and Siddiqui, F.H., (2017). Influence of biomass aggregate on strength of foam concrete. International Journal of Civil Engineering and Technology 8 (8), 1645-1653.

Amran, Y.H.M., Farzadnia, N. and Ali, A.A.A., (2015). Properties and applications of foamed concrete; A review. Construction and Building Materials, 101 , 990-1005. https://doi.org/10.1016/j.conbuildmat.2015.10.1 12

ASTM C1437, (2013). Standard test method for flow of hydraulic cement mortar, ASTM International.

ASTM C 1585-04, (2004). Standard test method for measurement of rate of absorption of water by hydraulic-cement concretes. ASTM International.

ASTM C348, (1998). Standard test method for flexural strength of hydraulic-cement mortars. ASTM International.

ASTM C349, (2002). Standard test method for compressive strength of hydraulic-cement mortars (Using portions of prisms broken in flexure). ASTM International.

ASTM C642-13, (2013). Standard test method for density, absorption, and voids in hardened concrete, ASTM International. ASTM International.

Bayraktar, O.Y., (2020). Pirinç kabuğu atıklarının köpük beton üretiminde kullanılması. Turkish Journal of Agriculture-Food Science, 8(12), 2716-2722.

https://doi.org/10.24925/turjaf.v8i12.27162722.4010

Chandni, T.J. and Anand, K.B., (2018). Utilization of recycled waste as filler in foam concrete. Journal of Building Engineering, 19, 154-160. https://doi.org/10.1016/j.jobe.2018.04.032

Chen, B. and Liu, N., (2013). A novel lightweight concrete-fabrication and its thermal and mechanical properties. Construction and Building Materials, 44, 691-698. https://doi.org/10.1016/j.conbuildmat.2013.03.0 91

Dong, Q., Huang, B. and Shu, X., (2013). Rubber modified concrete improved by chemically active coating and silane coupling agent. Construction and Building Materials 48, 116-123 https://doi.org/10.1016/j.conbuildmat.2013.06.0 72

Eltayeb, E., Ma, X., Zhuge, Y., Youssf, O. and Mills, J.E., (2020). Influence of rubber particles on the properties of foam concrete. Journal of Building Engineering, $\quad 30, \quad 101217$. https://doi.org/10.1016/j.jobe.2020.101217

EN 771-1, (2003). Specification for masonry units - Part 1: Clay masonry units. European Standard.

Ganjian, E., Khorami, M. and Maghsoudi, A.A., (2009). Scrap-tyre-rubber replacement for aggregate and filler in concrete. Construction and Building

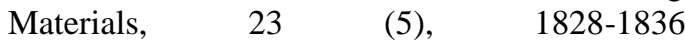
https://doi.org/10.1016/j.conbuildmat.2008.09.0 20

Gao, J.M., Qian, C.X., Liu, H.F., Wang, B. and Li, L., (2005). ITZ microstructure of concrete containing GGBS. Cement and Concrete $\begin{array}{llll}\text { Research } & 35 & \text { (7), } & \text { 1299-1304 }\end{array}$ https://doi.org/10.1016/j.cemconres.2004.06.04 2

Gesolu, M. and Güneyisi, E., (2011). Permeability properties of self-compacting rubberized concretes. Construction and Building Materials, $25 \quad$ (8), 3319-3326 https://doi.org/10.1016/j.conbuildmat.2011.03.0 21

Ghorbani, Saeid, Ghorbani, Sahar, Tao, Z., de Brito, J. and Tavakkolizadeh, M., (2019). Effect of magnetized water on foam stability and compressive strength of foam concrete. Construction and Building Materials, 197(10) 280-290. https://doi.org/10.1016/j.conbuildmat.2018.11.1 60

Giannakou A. and Jones M.R., (2002). Potential of foamed concrete to enhance the thermalperformance of low-rise dwellings. Innovations and Developments in Concrete Materials and Construction: Proceedings of the International Conference (pp. 533-544). Dundee.

Gowri, R. and Anand, K.B., (2018). Utilization of fly ash and ultrafine GGBS for higher strength foam concrete, in: IOP Conference Series: Materials Science and Engineering, 310. https://doi.org/10.1088/1757899X/310/1/012070

Gupta, T., Chaudhary, S. and Sharma, R.K., (2014). Assessment of mechanical and durability properties of concrete containing waste rubber tire as fine aggregate. Construction and Building $\begin{array}{lll}\text { Materials, } & 73 \quad \text { (30), 562-574. }\end{array}$ https://doi.org/10.1016/j.conbuildmat.2014.09.1 02 
Gupta, T., Sharma, R.K. and Chaudhary, S., (2015). Impact resistance of concrete containing waste rubber fiber and silica fume. International Journal of Impact Engineering, 83, 76-87. https://doi.org/10.1016/j.ijimpeng.2015.05.002

Gupta, T., Tiwari, A., Siddique, S., Sharma, R.K. and Chaudhary, S., (2017). Response assessment under dynamic loading and microstructural investigations of rubberized concrete. Journal of Materials in Civil Engineering, 29(8). https://doi.org/10.1061/(asce)mt.19435533.0001905

Hassanli, R., Youssf, O. and Mills, J.E., (2017). Experimental investigations of reinforced rubberized concrete structural members. Journal of Building Engineering, 10, 149-165. https://doi.org/10.1016/j.jobe.2017.03.006

Jiang, J., Lu, Z., Niu, Y., Li, J. and Zhang, Y., (2016). Study on the preparation and properties of highporosity foamed concretes based on ordinary Portland cement. Materials \& Design, 92, 949959.

https://doi.org/10.1016/j.matdes.2015.12.068

Jiang, Y., Ling, T.C., Shi, C. and Pan, S.Y., (2018). Characteristics of steel slags and their use in cement and concrete-A review. Resources, Conservation and Recycling 136, 187-197 https://doi.org/10.1016/j.resconrec.2018.04.023

Jones, M.R., Zheng, L. and Ozlutas, K., (2016). Stability and instability of foamed concrete. Magazine of Concrete Research, 68 (11) 542-549. https://doi.org/10.1680/macr.15.00097

Kaplan, G., Öztürk, A.U. ve Uğur Kaplan, A.B., (2020). Çimento ve uçucu kül bünyesindeki ağır metallerin etkilerinin hidratasyon ve çevre sağlığ1 açısından incelenmesi. Mühendislik Bilim. ve Tasarım Dergisi, 8(1), 305-313. https://doi.org/10.21923/jesd.512389

Khan, Q.S., Sheikh, M.N., McCarthy, T.J., Robati, M. and Allen, M., (2019). Experimental investigation on foam concrete without and with recycled glass powder: A sustainable solution for future construction. Construction and Building Materials, 201, 369-379. https://doi.org/10.1016/j.conbuildmat.2018.12.1 78

Kilincarslan, Ş., Davraz, M. and Akça, M., (2018). The effect of pumice as aggregate on the mechanical and thermal properties of foam concrete. Arabian Journal of Geosciences 11. https://doi.org/10.1007/s12517-018-3627-y

Kim, D.V., Cong, L.N., Van, L.T. and Bazhenova, S.I., (2020). Foamed concrete containing various amounts of organic-mineral additives. Journal of Physics: Conference Series, 1425. https://doi.org/10.1088/17426596/1425/1/012199

Krishnan, G. and Anand, K.B., (2018). Industrial waste utilization for foam concrete. IOP Conference Series: Materials Science and Engineering, 310. https://doi.org/10.1088/1757899X/310/1/012062

Lee YL, Hung YT., (2005). Exploitation of solid wastes with foamed concrete. London: Thomas Telford.

Li, P., Wu, H., Liu, Y., Yang, J., Fang, Z. and Lin, B., (2019). Preparation and optimization of ultralight and thermal insulative aerogel foam concrete. Construction and Building Materials, 205,

529-542. https://doi.org/10.1016/j.conbuildmat.2019.01.2 12

Majhi, R.K. and Nayak, A.N., (2020). Production of sustainable concrete utilising high-volume blast furnace slag and recycled aggregate with lime activator. Journal of Cleaner Production, 255. https://doi.org/10.1016/j.jclepro.2020.120188

Mashiri, M.S., Vinod, J.S., Sheikh, M.N. and Tsang, H.H., (2015). Shear strength and dilatancy behaviour of sand-tyre chip mixtures. Soils and Foundations, 55(3), 517-528. https://doi.org/10.1016/j.sandf.2015.04.004

Mehrani, S.A., Bhatti, I.A., Bhatti, N.B., Jhatial, A.A. and Lohar, M.A., (2019). Utilization of Rubber powder of waste tyres in foam concrete. Journal of Applied Engineering Sciences 9(22), 87-90. https://doi.org/10.2478/jaes-2019-0011

Mendis, A.S.M., Al-Deen, S. and Ashraf, M., (2018). Flexural shear behaviour of reinforced Crumbed Rubber Concrete beam. Construction and Building Materials, 166, 779-791. https://doi.org/10.1016/j.conbuildmat.2018.01.1 50

Nambiar, E.K.K. and Ramamurthy, K., (2007). Sorption characteristics of foam concrete. Cement and Concrete Research, 37(9), 1341-1347. https://doi.org/10.1016/j.cemconres.2007.05.01 0

Nambiar, E.K.K. and Ramamurthy, K., (2006). Influence of filler type on the properties of foam concrete. Cement and Concrete Composites, 28(5), 475-480. https://doi.org/10.1016/j.cemconcomp.2005.12. 001

Oikonomou, N. and Mavridou, S., (2009). The use of waste tyre rubber in civil engineering works. Sustainability of Construction Materials, 213238. https://doi.org/10.1533/9781845695842.213 
Pacheco-Torres, R., Cerro-Prada, E., Escolano, F. and Varela, F., (2018). Fatigue performance of waste rubber concrete for rigid road pavements. Construction and Building Materials, 176, 539548.

https://doi.org/10.1016/j.conbuildmat.2018.05.0 30

Pan, Z., Li, H. and Liu, W., (2014). Preparation and characterization of super low density foamed concrete from Portland cement and admixtures. Construction and Building Materials, 72, 256261.

https://doi.org/10.1016/j.conbuildmat.2014.08.0 78

Prim, P. and Wittmann, F. H., (1983). Structure and water absorption of aerated concrete. Wittmann F.H. (Ed.), Autoclaved Aerated Concrete, Moisture and Properties, (pp. 55-69). Elsevier.

Raj, A., Sathyan, D. and Mini, K.M., (2019). Physical and functional characteristics of foam concrete: A review. Construction and Building Materials, 221, 787-799. https://doi.org/10.1016/j.conbuildmat.2019.06.0 52

Ramamurthy, K., Kunhanandan Nambiar, E.K. and Indu Siva Ranjani, G., (2009). A classification of studies on properties of foam concrete. Cement and Concrete Composites, 31(6), 388-396. https://doi.org/10.1016/j.cemconcomp.2009.04. 006

Scott, E., (2016). End-of-life tyre report, european tyre $\&$ rubber manufacturers association, ETRMA.

Si, R., Wang, J., Guo, S., Dai, Q. and Han, S., (2018). Evaluation of laboratory performance of self- consolidating concrete with recycled tire rubber. Journal of Cleaner Production, 180, 823-831. https://doi.org/10.1016/j.jclepro.2018.01.180

Sofi, A., (2018). Effect of waste tyre rubber on mechanical and durability properties of concrete - A review. Ain Shams Engineering Journal, 9(4), 2691-2700. https://doi.org/10.1016/j.asej.2017.08.007

Tarasov, A.S., Kearsley, E.P., Kolomatskiy, A.S. and Mostert, H.F., (2010). Heat evolution due to cement hydration in foamed concrete. Magazine of Concrete Research, 62(12), 895-906. https://doi.org/10.1680/macr.2010.62.12.895

Van Deijk, S. (1992)., Foamed Concrete. Blackwater: A Dutch View, British Cement Association,

Vo, C. V., Bunge, F., Duffy, J. and Hood, L., (2011). Advances in thermal insulation of extruded polystyrene foams. Cellular Polymers, 30(3), 137-156. https://doi.org/10.1177/026248931103000303

Wakchaure, M.R. and Chavan, P.A., (2014). Waste tyre crumb rubber particle as a partial replacement to fine aggregate in concrete. International Journal of Engineering Research \& Technology, 3(6), 1206-1209.

Wei, S., Yiqiang, C., Yunsheng, Z. and Jones, M.R. (2013). Characterization and simulation of microstructure and thermal properties of foamed concrete. Construction and Building Materials, 47 ,

1278-1291. https://doi.org/10.1016/j.conbuildmat.2013.06.0 27 